\title{
The impact of physical activity on fatigue and quality of life in lung cancer patients: a randomised controlled trial protocol
}

\author{
Haryana M Dhillon ${ }^{1,4}$, Hidde P van der Ploeg ${ }^{2,3}$, Melanie L Bell ${ }^{4}$, Michael Boyer ${ }^{5}$, Stephen Clarke ${ }^{6,7}$ \\ and Janette Vardy ${ }^{1,4,5,6,8^{*}}$
}

\begin{abstract}
Background: People with lung cancer have substantial symptom burden and more unmet needs than the general cancer population. Physical activity (PA) has been shown to positively influence quality of life (QOL), fatigue and daily functioning in the curative treatment of people with breast and colorectal cancers and lung diseases, as well as in palliative settings. A randomised controlled trial (RCT) is needed to determine if lung cancer patients benefit from structured PA intervention. The Physical Activity in Lung Cancer (PAL) trial is designed to evaluate the impact of a 2-month PA intervention on fatigue and $\bar{Q} \mathrm{OL}$ in patients with non-resectable lung cancer. Biological mechanisms will also be studied.
\end{abstract}

Methods/design: A multi-centre RCT with patients randomised to usual care or a 2-month PA programme, involving supervised PA sessions including a behavioural change component and home-based PA. QOL questionnaires, disease and functional status and body composition will be assessed at baseline, 2, 4 and 6 months follow-up. The primary endpoint is comparative levels of fatigue between the 2 arms. Secondary endpoints include: $\mathrm{QOL}$, functional abilities and physical function. Exploratory endpoints include: anxiety, depression, distress, dyspnoea, PA behaviour, fitness, hospitalisations, survival, cytokines and insulin-like growth factor levels.

Discussion: This study will provide high-level evidence of the effect of PA programmes on cancer-related fatigue and QOL in patients with advanced lung cancer. If positive, the study has the potential to change care for people with cancer using a simple, inexpensive intervention to improve their $\mathrm{QOL}$ and help them maintain independent function for as long as possible.

Trial registration: Australian New Zealand Clinical Trials Registry No. ACTRN12609000971235

Keywords: Physical activity, Exercise, Fatigue, Quality of life, Lung cancer

\section{Background}

Lung cancer is the leading cause of cancer-related death worldwide. In the United States alone it was estimated there would be 226,160 new lung cancer cases and 160,340 lung cancer deaths in 2012 [1]. The majority (60\%) of lung cancer patients present with advanced, incurable disease resulting in a median survival of only 9-12 months [2]. In this context, the aim of anti-cancer

\footnotetext{
* Correspondence: janette.vardy@sydney.edu.au

${ }^{1}$ Centre for Medical Psychology and Evidence-based Decision-making,

University of Sydney, Sydney, Australia

${ }^{4}$ Psycho-Oncology Co-Operative Research Group (PoCoG), School of Psychology, Faculty of Science, University of Sydney, Sydney, Australia Full list of author information is available at the end of the article
}

treatment is to improve or maintain quality of life (QOL) in addition to prolonging survival.

Fatigue is one of the most common and distressing patient-reported symptoms associated with cancer and its treatment [3-5]. People with lung cancer report a higher prevalence and longer duration of cancer-related fatigue, leading to more functional impairment when compared to other cancer patients [6]. There is growing evidence that physical activity can improve fatigue in people with cancer, [7-9] and in those with chronic obstructive pulmonary disease (COPD) [10]. However, no study has evaluated the benefits of a lifestyle physical activity programme for people with non-resectable lung cancer. This study will

\section{Biomed Central}


determine if physical activity improves fatigue, in people with non-resectable lung cancer.

In the past five years several large observational studies have reported that physical activity reduces the risk of cancer recurrence, death from cancer, and death from all causes for breast and colon cancer patients [11-16]. These studies have shown consistently that more than 9 metabolic equivalent task (MET) hours/week of physical activity (e.g. walking at a moderate pace for 2.5 hours/ week) is associated with improved health outcomes. This is similar to the health guidelines of 150 minutes of moderate intensity physical activity per week or $60 \mathrm{~min}$ utes of vigorous physical activity per week [17].

A burgeoning literature has examined the effects of physical activity on supportive care outcomes in people with cancer including physical fitness, physical function, fatigue and QOL $[8,18-21]$. Observed benefits of physical activity include improved cardiovascular and pulmonary function, musculoskeletal strength, maintenance of mobility and independence, and improved psychological well-being and QOL $[9,22,23]$. Systematic reviews and meta-analyses have concluded that physical activity interventions during and after cancer therapies often result in meaningful and reliable improvements in several supportive care outcomes [8,9,19,20,22-25]. These benefits include observed changes in physiologic measures, objective performance indicators, self-reported functioning and symptoms, psychological well-being and overall QOL. However, these studies did not include people with advanced lung cancer.

A large body of evidence documents the benefits of physical activity as a component of pulmonary and cardiac rehabilitation in similar clinical populations, which demonstrate improved QOL, functional status, and symptom control including dyspnoea in patients with COPD. A Cochrane review of 31 randomised controlled trials in chronic obstructive pulmonary disease patients found those receiving pulmonary rehabilitation had statistically and clinically significant improvements in QOL, including dyspnoea, fatigue and patient control over disease [10].

Despite the benefits of physical activity, only $20-32 \%$ of all cancer survivors report meeting physical activity guidelines [18,26-28]. A recent study in lung cancer survivors found that $73 \%$ did not meet the United States physical activity guidelines, and $51 \%$ did not participate in any moderate or vigorous physical activity at all [29]. Lung cancer survivors who met the physical activity guidelines reported significantly better QOL across multiple domains compared to those who did not meet the guidelines [30]. This suggests that there are considerable opportunities for improving the physical activity behaviour of lung cancer patients and possibly improving their QOL.
Most physical activity studies have been performed in cancer populations with potentially curative disease, particularly breast and colorectal cancer survivors. By comparison, people with advanced incurable lung cancer are older (median age of 70 years) and more likely to have co-morbidities such as chronic obstructive pulmonary disease and cardiovascular disease. However, physical activity has been found to be beneficial in older cancer patients, [3] and in a palliative population [21]. Cardiopulmonary exercise testing in people with advanced cancer, including lung cancer, has been shown to be safe and feasible, which suggests that most people would be able to follow a programme emphasising moderate intensity physical activity [31].

The biological mechanisms by which physical activity may modify cancer risk or disease progression, or improve symptom control, include changes in insulin-like growth factor (IGF) levels, immune regulation, sex and metabolic hormone levels, prostaglandin ratio and obesity [16,32-35]. More specific to lung cancer, physical activity improves pulmonary function and perfusion, [36] and it is hypothesised that physical activity may upregulate antioxidants and free scavengers to help counteract the effects of cigarette smoke [37]. Physical activity may also decrease the risk of pneumonia and venothrombotic events, thereby improving overall survival and QOL in patients with non-resectable lung cancer.

Our aim is to evaluate a physical activity programme in people with non-resectable lung cancer to determine if it improves fatigue and quality of life. Our hypotheses are that people who undergo the physical activity intervention compared to those who do not, will: 1) report less fatigue; 2) have better health-related quality of life; 3) have improved overall survival; and, 4) have less decline in their level of physical function over time.

\section{Methods/design}

This multi-site, randomised controlled trial is being led by the Survivorship Research Group (SuRG) at the University of Sydney, Australia. Funding was obtained from a Young Investigator Award from the Lance Armstrong Foundation. The study was prospectively registered with the Australian New Zealand Clinical Trials Registry, registration number ACTRN12609000971235. Ethics approval has been obtained from Concord Repatriation General Hospital Human Research Ethics Committee for each participating institution under the New South Wales Health multi-site ethics approval scheme (HREC reference number: 08/CRGH/242).

Participants are recruited from lung cancer clinics at 4 Sydney hospitals, commencing May 2009 until achievement of planned sample size. 
Consenting, medically fit people with non-resectable lung cancer, including non-small cell lung cancer (NSCLC) and small cell lung cancer (SCLC) are randomised to usual care or a 2-month physical activity intervention (Figure 1). People with Stage III NSCLC or locally advanced SCLC being treated with curative intent must have completed combination chemo-radiotherapy a minimum of 4 weeks prior to randomisation, and have an incomplete response on staging CT scans. People with metastatic disease being treated palliatively may be receiving chemotherapy, radiotherapy and/or biological agents. All subjects must be medically fit to participate in a physical activity program, as assessed by the Physical Activity Readiness Questionnaire (PAR-Q) [38] and their treating physician. Major exclusion criteria are: Eastern Co-operative Oncology Group (ECOG) performance status $\geq 3$, life expectancy $<6$ months or insufficient English fluency to complete the questionnaires. Complete inclusion and exclusion criteria are outlined in Table 1. Randomisation is stratified for disease stage (locally advanced: NSCLC Stage III/ limited SCLC without a complete response to treatment versus metastatic disease: NSCLC Stage IV and extensive SCLC), ECOG performance status (0-1 versus 2), and cancer centre. It is performed by an external academic organisation using an interactive voice response system.

\section{Control - standard of care}

All participants will have routine follow-up as per local cancer centre practice and receive cancer-specific education materials regarding nutrition (Eat For Health) and exercise (Move Your Body) published by Cancer Council

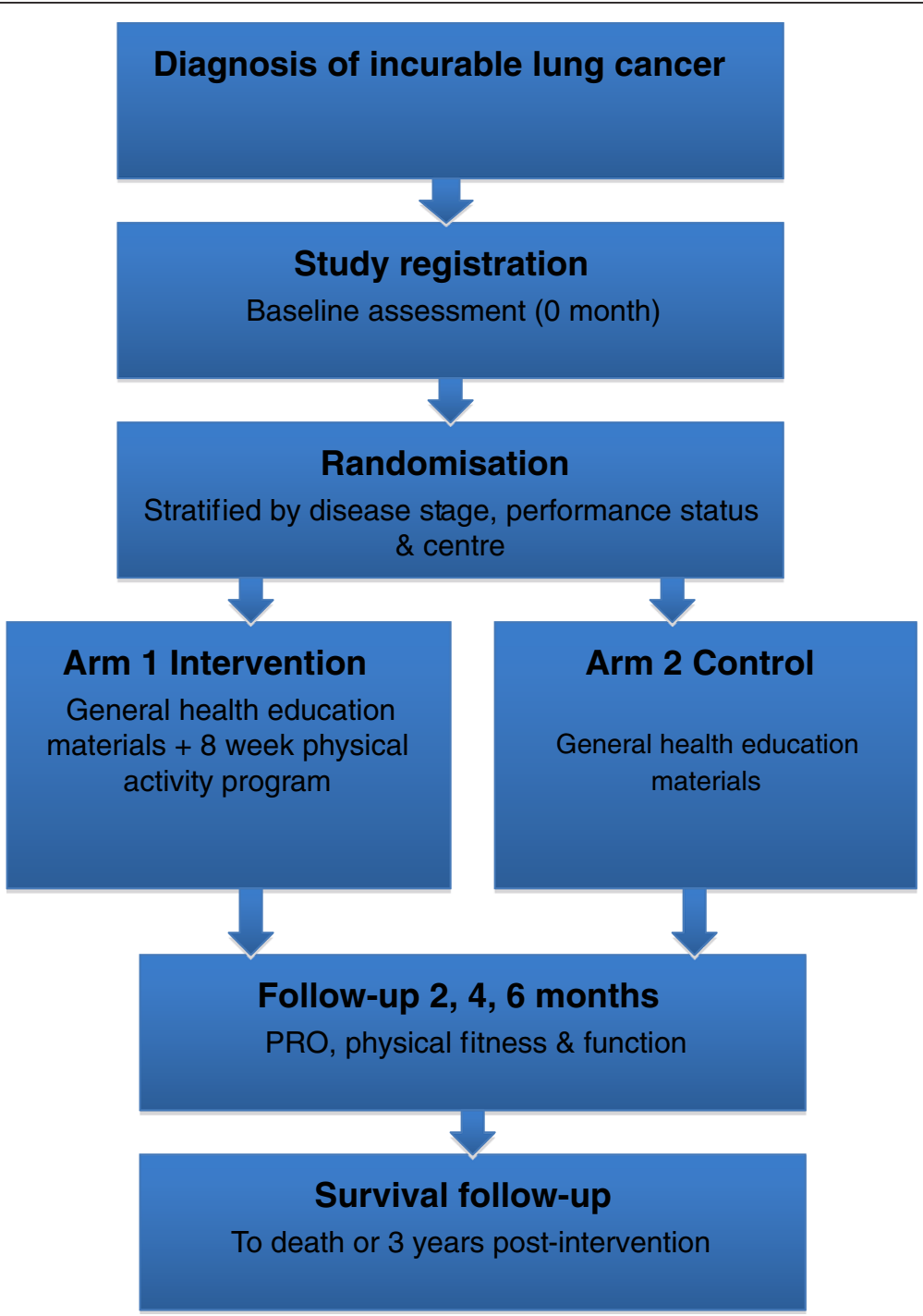

Figure 1 Study flowchart. PRO = patient reported outcomes. 
Table 1 Study inclusion and exclusion criteria

\begin{tabular}{|c|c|}
\hline Inclusion criteria & Exclusion criteria \\
\hline $\begin{array}{l}\text { Diagnosis of invasive lung cancer (NSCLC or SCLC) that, in the opinion of } \\
\text { the oncology team, is non-resectable and non-curable. }\end{array}$ & $\begin{array}{l}\text { European Co-operative Oncology Group (ECOG) } \\
\text { Performance Status of }>3 .\end{array}$ \\
\hline $\begin{array}{l}\text { People with Stage III NSCLC or limited SCLC who have evidence of residual } \\
\text { disease and have completed treatment with chemotherapy and or } \\
\text { radiotherapy a minimum of } 4 \text { weeks prior to commencing the study. }\end{array}$ & $\begin{array}{l}\text { Pre-existing significant co-morbid conditions precluding } \\
\text { participation in a physical activity programme, as determined } \\
\text { by the investigator. }\end{array}$ \\
\hline $\begin{array}{l}\text { People with advanced disease being treated palliatively may be receiving } \\
\text { chemotherapy, biological agents and/or best supportive care. }\end{array}$ & Insufficient English fluency to complete the questionnaires. \\
\hline Aged at least 18 years. & Life expectancy of $<6$ months. \\
\hline $\begin{array}{l}\text { Medically fit to participate in a physical activity programme, as determined } \\
\text { by their oncologist. }\end{array}$ & $\begin{array}{l}\text { Inability to complete the baseline exercise test } \\
\text { (6 Minute Walk) done prior to randomisation. }\end{array}$ \\
\hline \multicolumn{2}{|l|}{$\begin{array}{l}\text { Ability (i.e. sufficiently fluent) and willingness to complete the patient- } \\
\text { reported outcome questionnaires, physical activity questionnaires and logs in English. }\end{array}$} \\
\hline \multicolumn{2}{|l|}{ Give written informed consent. } \\
\hline \multicolumn{2}{|l|}{ Completion of the 3 Questionnaire assessment within 14 days of registration. } \\
\hline $\begin{array}{l}\text { Completion of the Physical Activity Readiness Questionnaire within } 14 \text { days of } \\
\text { registration. }\end{array}$ & \\
\hline
\end{tabular}

Australia (http://www.cancer.org.au/home.htm) to encourage adoption of a healthy lifestyle.

\section{Intervention}

\section{Theoretical framework}

The physical activity programme is based on the Theory of Planned Behaviour, [39] and modelled after the successful behaviour change programme developed by the Diabetes Prevention Programme [40].

Participants randomised to the physical activity intervention arm will participate in a 2 -month individualised physical activity and behavioural support programme with a Physical Activity Consultant (PAC).

The goal of the intervention will be to increase the participant's physical activity over the 2-month intervention by a minimum of 3 MET hours per week compared to baseline. While this may be less than the recommended physical activity guidelines for some participants, those capable of increasing their MET hours further will be encouraged to do so.

The physical activity program will consist of supervised physical activity (30 to 45 minutes duration) and behaviour support sessions (15 to 30 minutes) once a week for 8 weeks, as well as unsupervised home physical activity sessions. The physical activity program (including supervised and unsupervised sessions) will be tailored to the participant's baseline fitness, performance status and physical activity preferences, and take account of personal facilitators and barriers to physical activity. The study emphasises aerobic physical activity. Consequently it is expected that most participants will engage in walking as their preferred form of physical activity; however, other forms of aerobic activity such as swimming, cycling or running are acceptable. The program also incorporates advice about resistance exercises to encourage participants to maintain muscle function and strength.

The weekly structured sessions include physical activity as well as behaviour support sessions that use behaviour lifestyle change principles. It is the behaviour support sessions that will be the primary focus of the program promoting unsupervised physical activity. A full list of behaviour change session titles and their learning goals is outlined in Table 2. Participants will be supplied with a physical activity and behaviour change guidebook titled "Exercising with Lung Cancer", a pedometer and physical activity diary for use throughout the intervention.

\section{Assessments}

Outcomes will be assessed at baseline (prior to randomisation), 2, 4 and 6 months (Figure 1). Baseline assessments involve a medical history and examination. At all assessments, disease and treatment status will be recorded and subjects will complete patient reported outcome (PRO) questionnaires, a standardised fitness test (6 Minute Walk Test, [41] Senior's Fitness Test, [41] hand grip strength [42]), and donate blood for biomarker analysis. All subjects will wear an Actigraph GT1M accelerometer [43] (Actigraph LLC, Pensacola, FL, USA) on the right hip to objectively determine physical activity for 7 full days prior to each assessment. Survival status will be obtained from the medical records, with follow up until the time of the final analysis.

\section{Primary and secondary endpoints}

The primary endpoint will be the level of self-reported fatigue as assessed by the Functional Assessment of 
Table 2 Behaviour support sessions

\begin{tabular}{|c|c|c|}
\hline Session* & Session title & $\begin{array}{l}\text { Session learning goals } \\
\text { By the end of the session participants should have: }\end{array}$ \\
\hline \multirow[t]{5}{*}{1} & \multirow[t]{5}{*}{ Introduction to the program } & - Learned about the gymnasium / fitness facility; \\
\hline & & - Learned how to monitor intensity using the Borg Scale; \\
\hline & & - Learned how to properly stretch; \\
\hline & & - Learned about the PAL Study objectives; \\
\hline & & - Learned how to complete the daily PA Diary. \\
\hline \multirow[t]{3}{*}{2} & \multirow[t]{3}{*}{ Exercising properly } & - Learned what to wear when doing PA; \\
\hline & & - Learned the basics of proper hydration; \\
\hline & & - Learned about safety when doing PA. \\
\hline \multirow[t]{3}{*}{3} & \multirow[t]{3}{*}{ Goal setting and planning } & - Understood the importance of setting goals; \\
\hline & & - Learned how to create short and long term goals based on the SMART principle; \\
\hline & & - Learned how to create action steps to achieve a PA goal. \\
\hline \multirow[t]{3}{*}{4} & \multirow[t]{3}{*}{ Pedometers and walking } & - Learned about the health benefits of walking; \\
\hline & & - Learned how to use a pedometer; \\
\hline & & - Create a plan to increase the amount of steps per day. \\
\hline \multirow[t]{4}{*}{5} & \multirow{4}{*}{$\begin{array}{l}\text { Benefits of physical activity and overcoming barriers } \\
\text { to physical activity }\end{array}$} & - Understood the benefits of PA to the general population; \\
\hline & & - Learned more about the benefits of PA specific to people with lung cancer; \\
\hline & & - Identified what their personal barriers to PA are; \\
\hline & & - Worked through and brainstormed ideas how to overcome these barriers. \\
\hline \multirow[t]{2}{*}{6} & \multirow[t]{2}{*}{ Environmental scan } & - Learned what PA opportunities exist in their local environment; \\
\hline & & - Learned how to make use of indoor fitness facilities or sports stores. \\
\hline \multirow[t]{4}{*}{7} & \multirow[t]{4}{*}{ Social support and having fun with physical activity } & - Learned the importance of social support for maintaining a PA program; \\
\hline & & - Identified what social support they may be able to utilise; \\
\hline & & - Identified what makes PA fun for them; \\
\hline & & - Brainstormed how to increase their enjoyment of PA. \\
\hline \multirow[t]{4}{*}{8} & \multirow[t]{4}{*}{ Stimulus control and decision balance sheet } & - Learned what stimulus control is and how it affects behaviour; \\
\hline & & - Learned how to establish appropriate stimuli; \\
\hline & & - Understood the benefits of using a decision balance sheet; \\
\hline & & - Learned how to create and use a decision balance sheet for themselves. \\
\hline
\end{tabular}

* Order of behaviour change session delivery can be tailored to suit the most pressing educational and behavioural needs of participants.

Cancer Therapy - fatigue (FACT-F) subscale [44,45]. The primary outcome will be a comparison of fatigue in the intervention and control arms at the conclusion of the intervention (i.e. at the 2-month assessment).

Secondary endpoints will include the following Patient Reported Outcomes:

- QOL (European Organisation for Research and Treatment of Cancer -Quality of life questionnaire Core (EORTC-QLQ-C30) and Lung module (LC-13 subscale) [46],

- activities of daily living and instrumental activities of daily living[47].

- physical function (6 Minute Walk Test) [41].

Other exploratory endpoints relating to physical activity and fitness will include:
- anxiety and depression (General Health Questionnaire 12) [48];

- distress (Distress Thermometer) [49],

- perceived cognitive function (FACT-Cognition v3) [50],

- sleep quality (Pittsburgh Sleep Quality Index) [51],

- dyspnoea (University of California San Diego Shortness of Breath Questionnaire [52] and physical activity and sedentary behaviour (Actigraph GT1M accelerometer; Active Australia questionnaire [53], sedentary behaviour questionnaire [54]);

- physical activity attitudes (Social Cognitive Determinants of Exercise questionnaire) [30,55]

- physical fitness (6 Minute Walk Test, Seniors Fitness Test, [41] hand grip strength);

- pulmonary function (Forced Expiratory Volume in 1 second, Forced Vital Capacity); 
- general health, functional and performance status (anthropmetric measurements, Colinet co-morbidity score [56], ECOG performance status, admissions to hospital/hospice and survival data); and

- mechanisms and prognostic biomarkers (Glasgow Prognostic Score [C-reactive protein, albumin], selected cytokine levels, insulin-like growth factors).

Table 3 gives an overview of all outcome assessments.

\section{Statistical analysis \\ Sample size}

A sample size of 72 evaluable participants (36/arm) provides $80 \%$ power (two-tailed $\alpha 0.05$ ) to detect a difference of 6 points (FACT-F subscale range: $0-52$ ) in the primary outcome measure of fatigue between the two treatment arms at 2 months and assuming a standard deviation of 9 [57]. This is a standardized effect size of 0.67 , thus each of the secondary outcomes is also powered at this level. Due to the poor prognosis for this patient population we need to increase our enrolment by $30 \%$ to account for attrition. Therefore, in total we will aim to recruit $\sim 102$ patients.

\section{Statistical analyses}

We report only on analyses for the primary and three secondary outcomes: fatigue, quality of life, activities of daily living, and the six minute walk test. Because of the potential for informative dropout, rigorous methods which account for missing data will be employed. There are three type of missing data. Data are missing completely at random (MCAR) if missing values and

Table 3 Assessments

\begin{tabular}{|c|c|c|}
\hline & Investigations & Timing \\
\hline \multirow{9}{*}{$\begin{array}{l}\text { History and Physical } \\
\text { Exam including: }\end{array}$} & - Height (baseline only) & \multirow[t]{9}{*}{$0,2,4,6$ months } \\
\hline & - Weight and Body Mass Index (BMI) & \\
\hline & - Blood Pressure and Heart Rate & \\
\hline & - Oxygen saturation ( $\mathrm{SaO} 2$ ) (on room air) & \\
\hline & - Concomitant medications (any changes to baseline meds) & \\
\hline & - Colinet Co-morbidity Score & \\
\hline & - Eastern Cooperative Oncology Group Performance Status (ECOG PS) & \\
\hline & - Disease status & \\
\hline & - Current treatments & \\
\hline \multirow[t]{3}{*}{ Fitness Testing } & • 6-minute walk test (6MWT) & \multirow[t]{3}{*}{$0,2,4,6$, months } \\
\hline & - Senior's Fitness Test & \\
\hline & - Hand grip strength & \\
\hline \multirow[t]{2}{*}{ Pulmonary Function } & - Forced Expiratory Volume at 1 second $\left(\mathrm{FEV}_{1}\right)$ & \multirow[t]{2}{*}{$0,2,4,6$ months } \\
\hline & - Forced Vital Capacity (FVC) & \\
\hline Adverse Events & $\begin{array}{l}\text { - Adverse events will be recorded and graded using National Cancer Institute Common Terminology } \\
\text { Criteria for Adverse Events Version 3.0 ( } \mathrm{NCl} \mathrm{CTCAE} \mathrm{v3.0)}\end{array}$ & $0,2,4,6$ months \\
\hline \multirow{10}{*}{$\begin{array}{l}\text { Patient Reported } \\
\text { Outcomes }\end{array}$} & - Functional Assessment of Cancer Therapy - Fatigue (FACT-F subscale) & \multirow[t]{10}{*}{$0,2,4,6$ months } \\
\hline & $\begin{array}{l}\text { - Quality of Life (QOL) European Organisation for Research and Treatment of Cancer -Quality of life } \\
\text { questionnaire - Core (EORTC-QLQ-C30) and Lung module (LC-13 subscale) }\end{array}$ & \\
\hline & - Depression and Anxiety (General Health Questionnaire - GHQ12) & \\
\hline & - Sleep Quality (Pittsburgh Sleep Quality Index - PSQI) & \\
\hline & - Cognitive Function (Functional Assessment of Cancer Therapy - Cognitive scale - FACT-COG v3) & \\
\hline & - Distress (Distress Thermometer) & \\
\hline & - Dyspnoea (The University of California, San Diego Shortness of Breath Questionnaire -SOBQ) & \\
\hline & - Activities of Daily Living (ADLs) and Independent Activities of Daily Living (IADLs) & \\
\hline & - Sedentary time (Sitting Questionnaire) & \\
\hline & - Physical activity attitudes (Social Cognitive Determinants of Exercise questionnaire) & \\
\hline \multirow{2}{*}{$\begin{array}{l}\text { Physical Activity Behaviour/ } \\
\text { Adherence }\end{array}$} & - Physical activity participation (Active Australia) & \multirow[t]{2}{*}{$0,2,4,6$ month } \\
\hline & - Accelerometer -for one week prior to each assessment & \\
\hline \multirow[t]{2}{*}{ Other Investigations } & - Fasting Serum/plasma collection for correlative studies and optional banking & \multirow[t]{2}{*}{$0,2,4,6$ months } \\
\hline & - Glasgow Prognostic score: Full blood count (FBC), Albumin, C-reactive protein (CRP) & \\
\hline
\end{tabular}


observed value are not systematically different. Data are missing at random (MAR) if any systematic differences can be explained by observed outcome or covariate data. Data are missing not at random (MNAR) when systematic differences exist, even after adjusting for previously observed data. A MAR primary analysis followed by sensitivity analyses are recommended by experts in the field of missing data [58].

Thus, our main analyses will use linear mixed models for all outcomes, which are unbiased for data which are MCAR or MAR and are consistent with the intentionto-treat principle [58-60]. Mixed model account for covariance between repeated measures on patients and allow for: 1) comparing patterns of change over time by testing the intervention group by time interaction; and 2) estimating and testing differences between groups at time points of interest via linear contrasts. Unadjusted and adjusted main analyses will be carried out, with adjustment for baseline measures including sex, age, disease stage, and the baseline outcome.

Patterns of missing data will be assessed to consider potential missing data mechanisms and baseline characteristics of patients lost to follow-up at 2, 4 and 6 months will be compared to patients who completed follow-up to assess patterns of loss to follow-up. Sensitivity analyses will be carried out using multiple imputation, which will include auxiliary data such as ECOG performance status and baseline secondary outcomes such as physical activity measures.

Overall survival is an exploratory endpoint, because the study has limited power to evaluate this. Patients alive at final analysis or who have become lost to follow up will be censored at their last contact date. Overall survival will be described by the Kaplan-Meier method. A stratified logrank test adjusting for the stratification factors of disease stage (locally advanced vs metastatic) and ECOG performance status $(0+1$ vs 2$)$ at randomisation will be used to compare overall survival between the two arms.

\section{Discussion}

Advanced lung cancer is incurable, and is the leading cause of cancer deaths world-wide. The goal of treatment is to improve QOL, maintain physical function and prolong life. Treatments to date have focused on disease modifying anti-cancer therapies (e.g. chemotherapy or radiation). A focus on the person and their functional status reflects an innovative approach to therapy, maximising their ability to live with miminal effects of the disease for as long as possible.

A physically active lifestyle improves fatigue and QOL in other cancer populations, particularly in early stage disease, but this type of intervention has not been evaluated in advanced lung cancer, where people are generally older with a higher burden of co-morbid illnesses than other cancer groups. This intervention has the potential to change standard care with a simple, safe, relatively inexpensive treatment that could improve the QOL of people with lung cancer and help them to maintain independent function for as long as possible. This study will determine whether a physical activity programme reduces the number of days participants spend in hospital for symptom control and end of life care. It will obtain unique data about the impact of physical activity on cytokines and the insulin pathway and the influence of each of these biomarkers on prognosis. It will provide preliminary evidence on whether physical activity can impact on survival in people with lung cancer.

One of the greatest challenges to implementation of physical activity programmes has been availability of adequate support and resources to promote and maintain adherence with physical activity. If a randomised controlled trial demonstrated a significant benefit for people with lung cancer this would not only provide great impetus to patients to increase their physical activity and oncologists to promote it, but provide an evidence base to support a change in policy and practice to ensure patients engage with a physical activity consultant to design and follow-up a personalised physical activity programme. The intervention under study has been designed to ensure it can be offered in a hospital or community setting.

\section{Conclusions}

Physical activity has been associated with many health benefits. This study will provide high-level evidence of the effectiveness of physical activity programmes to improve cancer fatigue and QOL in a cancer population with substantial symptom burden and high unmet needs. It will determine the feasibility of delivering exercise programmes in an advanced lung cancer population, and be powered to evaluate whether physical activity improves fatigue and QOL in this patient population. In addition, it will obtain important data about the impact of physical activity on physical function, body composition, mood, perceived cognitive function, dyspnoea, cytokines and the insulin pathway, and their influence on prognosis. The study outcomes have the potential to change standard care, with a non-toxic and inexpensive treatment, which can improve quality of life of people with lung cancer and help them achieve the highest possible level of independent function for as long as possible [61].

Competing interests

None of the authors has a conflict of interest to declare.

Authors' contributions

HD and JV devised the study concept and design. All authors contributed to the study protocol. M.Bell was responsible for overseeing the statistical section. HD, HVP, M.Bell and JV wrote the manuscript. All authors read and approved the final manuscript. 


\section{Acknowledgements}

The study has received funding from the Lance Armstrong Foundation / National Lung Cancer Alliance Partnership.

A/Prof. Janette Vardy is funded by the Cancer Institute NSW and Dr Haryana Dhillon received funding from the Australasian Lung Trials Group and Psycho-Oncology Co-Operative Research Group (PoCoG). Dr Hidde van der Ploeg was supported by an Australian National Health and Medical Research Council programme grant (\#301200).

An equipment grant was received from the Sydney Cancer Centre Foundation for purchase of gymnasium equipment for use by trial participants.

\section{Author details}

${ }^{1}$ Centre for Medical Psychology and Evidence-based Decision-making, University of Sydney, Sydney, Australia. ${ }^{2}$ Sydney School of Public Health, University of Sydney, Sydney, Australia. ${ }^{3}$ Department of Public and Occupational Health, VU University Medical Center Amsterdam, Amsterdam, The Netherlands. ${ }^{4}$ Psycho-Oncology Co-Operative Research Group (PoCoG), School of Psychology, Faculty of Science, University of Sydney, Sydney, Australia. ${ }^{5}$ Sydney Cancer Centre, Sydney, Australia. ${ }^{6}$ Sydney Medical School, University of Sydney, Sydney, Australia. ${ }^{7}$ Royal North Shore Hospital, St Leonards, Australia. ${ }^{8}$ Sydney Cancer Centre, Concord Repatriation General Hospital, Hospital Rd, Concord, NSW 2137, Australia.

Received: 4 July 2012 Accepted: 26 November 2012

Published: 5 December 2012

\section{References}

1. Society AC: Cancer facts \& figures 2012. Atlanta: American Cancer Society; 2012.

2. Gloeckler LA, Eisner MP: Cancer of the lung. In SEER Survival Monograph: Cancer Sunvival Among Adults: US SEER Program, 1988-2001, Patient and Tumor Characteristics. Volume NIH Pub. No. 07-6215. Edited by Ries LAG, Young JL, Keel GE, Eisner MP, Lin YD, Horner M-J. Bethesda, MD: National Cancer Institute, SEER Program; 2007.

3. Luctkar-Flude MF, Groll DL, Tranmer JE, Woodend K: Fatigue and physical activity in older adults with cancer: a systematic review of the literature. Cancer Nurs 2007, 30(5):E35-45.

4. Joyce M, Schwartz S, Huhmann M: Supportive care in lung cancer. Semin Oncol Nurs 2008, 24(1):57-67.

5. Hofman M, Ryan JL, Figueroa-Moseley CD, Jean-Pierre P, Morrow GR: Cancer-related fatigue: the scale of the problem. Oncologist 2007, 12(Suppl 1):4-10.

6. Forlenza MJ, Hall P, Lichtenstein P, Evengard B, Sullivan PF: Epidemiology of cancer-related fatigue in the Swedish twin registry. Cancer 2005, 104(9):2022-2031.

7. Dimeo F, Schwartz S, Wesel N, Voigt A, Thiel E: Effects of an endurance and resistance exercise program on persistent cancer-related fatigue after treatment. Ann Oncol 2008, 19:1495-1499.

8. Galvao DA, Newton RU: Review of exercise intervention studies in cancer patients. J Clin Oncol 2005, 23(4):899-909.

9. Stevinson C, Lawlor DA, Fox KR: Exercise interventions for cancer patients: systematic review of controlled trials. Cancer Causes Control 2004, 15(10):1035-1056.

10. Lacasse $Y$, Goldstein R, Lasserson TJ, Martin S: Pulmonary rehabilitation for chronic obstructive pulmonary disease. Cochrane Database Syst Rev 2006, (4):CD003793.

11. Holmes MD, Chen WY, Feskanich D, Kroenke CH, Colditz GA: Physical activity and survival after breast cancer diagnosis. JAMA 2005, 293(20):2479-2486.

12. Meyerhardt JA, Giovannucci EL, Holmes MD, Chan AT, Chan JA, Colditz GA Fuchs CS: Physical activity and survival after colorectal cancer diagnosis. J Clin Oncol 2006, 24(22):3527-3534

13. Meyerhardt JA, Heseltine D, Niedzwiecki D, Hollis D, Saltz LB, Mayer RJ, Thomas J, Nelson H, Whittom R, Hantel A, et al: Impact of physical activity on cancer recurrence and survival in patients with stage III colon cancer: findings from CALGB 89803. J Clin Oncol 2006, 24(22):3535-3541.

14. Haydon AM, Macinnis RJ, English DR, Giles GG: Effect of physical activity and body size on survival after diagnosis with colorectal cancer. Gut 2006, 55(1):62-67.
15. Meyerhardt JA, Giovannucci EL, Ogino S, Kirkner GJ, Chan AT, Willett W, Fuchs CS: Physical activity and male colorectal cancer survival. Arch Intern Med 2009, 169(22):2102-2108.

16. Ballard-Barbash R, Friedenreich CM, Courneya KS, Siddiqi SM, McTiernan A, Alfano CM: Physical activity, biomarkers, and disease outcomes in cancer survivors: a systematic review. J Natl Cancer Inst 2012, 104:815-840.

17. World Health Organisation: Global recommendations on physical activity for health. Geneva, Switzerland: World Health Organization; 2010.

18. Lynch BM, Cerin E, Owen N, Aitken JF: Associations of leisure-time physical activity with quality of life in a large, population-based sample of colorectal cancer survivors. Cancer Causes Control 2007, 18(7):735-742.

19. Courneya KS, Friedenreich CM, Quinney HA, Fields AL, Jones LW, Fairey AS: A randomized trial of exercise and quality of life in colorectal cancer survivors. Eur J Cancer Care 2003, 12(4):347-357.

20. Knols R, Aaronson NK, Uebelhart D, Fransen J, Aufdemkampe G: Physical exercise in cancer patients during and after medical treatment: $a$ systematic review of randomized and controlled clinical trials. J Clin Oncol 2005, 23(16):3830-3842.

21. Oldervoll LM, Loge JH, Paltiel H, Asp MB, Vidvei U, Wiken AN, Hjermstad MJ, Kaasa S: The effect of a physical exercise program in palliative care: a phase II study. J Pain Symptom Manage 2006, 31(5):421-430.

22. Wiggins MS, Simonavice EM: Cancer prevention, aerobic capacity, and physical functioning in survivors related to physical activity: a recent review. Cancer Manage Res 2010, 2:157-164.

23. Speck RM, Courneya KS, Masse LC, Duval S, Schmitz KH: An update of controlled physical activity trials in cancer survivors: a systematic review and meta-analysis. J Cancer Surviv: Res and Pract 2010, 4(2):87-100.

24. Schmitz KH, Holtzman J, Courneya KS, Masse LC, Duval S, Kane R: Controlled physical activity trials in cancer survivors: a systematic review and meta-analysis. Cancer Epidemiol Biomarkers Prev 2005, 14(7):1588-1595.

25. Schmitz KH, Courneya KS, Matthews C, Demark-Wahnefried W, Galvao DA, Pinto BM, Irwin ML, Wolin KY, Segal RJ, Lucia A, et al: American College of Sports Medicine roundtable on exercise guidelines for cancer survivors. Med Sci in Sports Exerc 2010, 42(7):1409-1426.

26. Bellizzi KM, Rowland JH, Jeffery DD, McNeel T: Health behaviors of cancer survivors: examining opportunities for cancer control intervention. J Clin Oncol 2005, 23(34):8884-8893.

27. Courneya KS, Katzmarzyk P, Bacon E: Physical activity and obesity in canadian cancer survivors: population-based estimates from the 2005 canadian community health survey. Cancer 2008, 112(11):2475-82.

28. Coups EJ, Ostroff JS: A population-based estimate of the prevalence of behavioral risk factors among adult cancer survivors and noncancer controls. Prev Med 2005, 40(6):702-711.

29. Oh B, Butow P, Mullan B, Clarke S, Beale P, Pavlakis N, Kothe E, Lam L, Rosenthal D: Impact of medical Qigong on quality of life, fatigue, mood and inflammation in cancer patients: a randomized controlled trial. Ann Oncol 2012, 21(3):608-614.

30. Azjen I: The theory of planned behavior. Organ Behav Hum Decis Process 1991, 50:179-211.

31. Jones LW, Eves ND, Mackey JR, Peddle CJ, Haykowsky M, Joy AA, Courneya KS, Tankel K, Spratlin J, Reiman T: Safety and feasibility of cardiopulmonary exercise testing in patients with advanced cancer. Lung cancer (Amsterdam, Netherlands) 2007, 55(2):225-232.

32. McTiernan A: Mechanisms linking physical activity with cancer. Nat Rev 2008, 8(3):205-211.

33. Friedenreich $\mathrm{CM}$, Orenstein MR: Physical activity and cancer prevention: etiologic evidence and biological mechanisms. J Nutr 2002, 132(11 Suppl):3456S-3464S

34. Fairey AS, Courneya KS, Field CJ, Bell GJ, Jones LW, Mackey JR: Effects of exercise training on fasting insulin, insulin resistance, insulin-like growth factors, and insulin-like growth factor binding proteins in postmenopausal breast cancer survivors: a randomized controlled trial. Cancer Epidemiol Biomarkers Prev 2003, 12(8):721-727.

35. Irwin ML, Varma K, Alvarez-Reeves M, Cadmus L, Wiley A, Chung GG, Dipietro L, Mayne ST, Yu H: Randomized controlled trial of aerobic exercise on insulin and insulin-like growth factors in breast cancer survivors: the yale exercise and survivorship study. Cancer Epidemiol Biomarkers Prev 2009, 18(1):306-313.

36. Jakes RW, Day NE, Patel B, Khaw KT, Oakes S, Luben R, Welch A, Bingham S, Wareham NJ: Physical inactivity is associated with lower forced expiratory volume in 1 second: European prospective investigation into 
cancer-Norfolk prospective population study. Am J Epidemiol 2002, 156(2):139-147.

37. Morrow JD, Frei B, Longmire AW, Gaziano JM, Lynch SM, Shyr Y, Strauss WE, Oates JA, Roberts $L J$ 2nd: Increase in circulating products of lipid peroxidation (F2-isoprostanes) in smokers. Smoking as a cause of oxidative damage. N Engl J Med 1995, 332(18):1198-1203.

38. Thomas S, Reading J, Shephard RJ: Revision of the physical activity readiness questionnaire (PAR-Q). Can J Sport Sci $=$ Journal canadien des sciences du sport 1992, 17(4):338-345.

39. Ajzen I: The theory of planned behavior. Organ Behav Hum Decis Process 1991, 50:179-211.

40. Knowler WC, Barrett-Connor E, Fowler SE, Hamman RF, Lachin JM, Walker EA, Nathan DM: Reduction in the incidence of type 2 diabetes with lifestyle intervention or metformin. N Engl J Med 2002, 346(6):393-403.

41. Rikli R, Jones CJ: Senior fitness test manual. Champaign, IL: Human Kinetics; 2001.

42. Bohannon RW: Hand-grip dynamometry provides a valid indication of upper extremity strength impairment in home care patients. $J$ Hand Ther: official journal of the American Society of Hand Therapists 1998, 11(4):258-260.

43. Plasqui $\mathrm{G}$, Westerterp KR: Physical activity assessment with accelerometers: an evaluation against doubly labeled water. Obes (Silver Spring) 2007, 15(10):2371-2379.

44. Yellen SB, Cella DF, Webster K, Blendowski C, Kaplan E: Measuring fatigue and other anemia-related symptoms with the Functional Assessment of Cancer Therapy (FACT) measurement system. J Pain Symptom Manage 1997, 13(2):63-74

45. Cella D, Davis K, Breitbart W, Curt G: Cancer-related fatigue: prevalence of proposed diagnostic criteria in a United States sample of cancer survivors. J Clin Oncol 2001, 19(14):3385-3391.

46. Bergman B, Aaronson NK, Ahmedzai S, Kaasa S, Sullivan M: The EORTC QLQ-LC13: a modular supplement to the EORTC core quality of life questionnaire (QLQ-C30) for use in lung cancer clinical trials. EORTC study group on quality of life. Eur J Cancer 1994, 30A(5):635-642

47. Thomas VS, Rockwood K, McDowell I: Multidimensionality in instrumental and basic activities of daily living. J Clin Epidemiol 1998, 51(4):315-321.

48. Goldberg DP: A user's guide to the general health questionnaire. Windsor, UK: NFER-Nelson; 1991

49. Tuinman MA, Gazendam-Donofrio SM, Hoekstra-Weebers JE: Screening and referral for psychosocial distress in oncologic practice: use of the distress thermometer. Cancer 2008, 113(4):870-878.

50. Wagner $L$, Sweet J, Butt $Z$, Lai J, Cella D: Measuring patient self-reported cognitive function: development of the functional assessment of cancer therapy - cognitive function instrument. J Support Oncol 2009, 7(6):W32-W39.

51. Buysse DJ, Reynolds CF 3rd, Monk TH, Berman SR, Kupfer DJ: The pittsburgh sleep quality index: a new instrument for psychiatric practice and research. Psychiatry Res 1989, 28(2):193-213.

52. Eakin EG, Resnikoff PM, Prewitt LM, Ries AL, Kaplan RM: Validation of a new dyspnea measure: the UCSD shortness of breath questionnaire. University of California, San Diego. Chest 1998, 113(3):619-624.

53. Brown WJ, Trost SG, Bauman A, Mummery K, Owen N: Test-retest reliability of four physical activity measures used in population surveys. J Sci Med Sport / Sports Med Aust 2004, 7(2):205-215.

54. Marshall AL, Miller YD, Burton NW, Brown WJ: Measuring total and domain-specific sitting: a study of reliability and validity. Med Sci Sports Exerc 2010, 42(6):1094-1102.

55. Courneya KS, Friedenreich CM, Reid RD, Gelmon K, Mackey JR, Ladha AB, Proulx C, Vallance JK, Segal RJ: Predictors of follow-up exercise behavior 6 months after a randomized trial of exercise training during breast cancer chemotherapy. Breast Cancer Res Treat 2009, 114:179-187.

56. Colinet B, Jacot W, Bertrand D, Lacombe S, Bozonnat MC, Daures JP, Pujol $J \mathrm{~L}$ : A new simplified comorbidity score as a prognostic factor in nonsmall-cell lung cancer patients: description and comparison with the Charlson's index. Br J Cancer 2005, 93(10):1098-1105.

57. Cella D, Eton DT, Lai JS, Peterman AH, Merkel DE: Combining anchor and distribution-based methods to derive minimal clinically important differences on the Functional Assessment of Cancer Therapy (FACT) anemia and fatigue scales. J Pain Symptom Manage 2002, 24(6):547-561.

58. National Research Council: Panel on handling missing data in clinical trials. The prevention and treatment of missing data in clinical trials, Committee on national statistics, division of behavioral and social sciences and education. Washington DC: Pres NA; 2010.

59. Fitzmaurice GM, Laird NM, Ware JH: Applied longitudinal analysis. 2nd edition. Hoboken NJ: Wiley; 2011.

60. White IR, Horton NJ, Carpenter J, Pocock SJ: Strategy for intention to treat analysis in randomised trials with missing outcome data. BMJ 2011, 342: 440 .

61. Ries AL, Bauldoff GS, Carlin BW, Casaburi R, Emery CF, Mahler DA, Make B, Rochester CL, Zuwallack R, Herrerias C: Pulmonary rehabilitation: joint ACCP/AACVPR evidence-based clinical practice guidelines. Chest 2007, 131(5 Suppl):4S-42S

doi:10.1186/1471-2407-12-572

Cite this article as: Dhillon et al:: The impact of physical activity on fatigue and quality of life in lung cancer patients: a randomised controlled trial protocol. BMC Cancer 2012 12:572.

\section{Submit your next manuscript to BioMed Central and take full advantage of:}

- Convenient online submission

- Thorough peer review

- No space constraints or color figure charges

- Immediate publication on acceptance

- Inclusion in PubMed, CAS, Scopus and Google Scholar

- Research which is freely available for redistribution 